\title{
Thermal neutron irradiation effects on structural and electrical properties of n-type $4 \mathrm{H}-\mathrm{SiC}$
}

\author{
Indudhar Panduranga Vali ${ }^{1} \cdot$ Pramoda Kumara Shetty $^{2} \cdot$ M. G. Mahesha ${ }^{2} \cdot$ Mala N. Rao $^{3} \cdot$ Swayam Kesari $^{3}$
}

Received: 26 February 2020 / Accepted: 9 April 2020 / Published online: 20 April 2020

(c) The Author(s) 2020

\begin{abstract}
In this article, the thermal neutron irradiation (NI) effects on the structural properties of $\mathrm{n}-4 \mathrm{H}-\mathrm{SiC}$ and electrical properties of $\mathrm{Al} / \mathrm{n}-4 \mathrm{H}-\mathrm{SiC}$ Schottky contacts have been reported. The noticeable modifications observed in the irradiated samples were studied by using different techniques. The X-ray diffraction studies revealed a decrease in the lattice parameter of the irradiated samples due to isotopic modifications and irradiation-induced defects in the material. As a result, the energy bandgap, Urbach energy, longitudinal optical phonon-plasmon coupling mode, free carrier concentration, defect related photoluminescence and nitrogen bound exciton photoluminescence bands were prominently affected in the irradiated samples. The current-voltage characteristics of neutron irradiated $\mathrm{Al} / \mathrm{n}-4 \mathrm{H}-\mathrm{SiC}$ Schottky contacts were also strikingly affected in terms of zero-bias offset as well as decrease in the forward current. These modifications along with the increase in the Schottky junction parameters (such as ideality factor, Schottky barrier height and series resistance) were attributed to neutron-induced isotopic effects and decrease in the free carrier concentration due to induced defect states.
\end{abstract}

\section{Introduction}

In the last two decades the irradiation studies on silicon carbide $(\mathrm{SiC})$, particularly $4 \mathrm{H}-\mathrm{SiC}$ polytype and its electronic devices have greatly attracted the research community. Due to superior physical properties [1] and high displacement threshold energy [2], the $4 \mathrm{H}-\mathrm{SiC}$ based electronic devices [3-10] were studied and are still being examined under different irradiation environments, with different irradiation parameters as well as under different temperature conditions. The performance of such devices are known to be affected by grown-in defects, irradiation-induced defects and issues with the metal contacts.

Compared to other radiations such as electrons, gammarays and heavy ions, the neutrons are known to cause significant modifications in the material properties. Such

Pramoda Kumara Shetty

pramod.shetty@manipal.edu

1 Department of Physics, KLE Society's S. Nijalingappa College, Bangalore 560010, India

2 Department of Physics, Manipal Institute of Technology, Manipal Academy of Higher Education, Manipal 576104, India

3 Solid State Physics Division, Bhabha Atomic Research Centre, Mumbai 400085, India modifications are found to depend on the nature of material as well as irradiation parameters such as neutron energy, neutron flux and irradiation temperature. In general, the fast neutrons greatly disturb the periodic structure of a crystalline material due to displacement damage effects. While the low energy neutrons such as thermal neutrons can move through the crystalline material without displacing any host atoms. But in the end the capturing of thermal neutrons by atomic nucleus will lead to the formation different isotopes and/or transmutation into new element in the exposed material. However, the fast neutrons, which are present in the reactor flux of thermal neutrons can cause displacement effects in the crystalline material and therefore generates defects such as vacancies, or cluster of vacancies and interstitials, or defects involving impurities present in the material [11]. Subsequently, the examination of thermal neutroninduced modifications in the material properties turns out to be questionable.

The examination of material properties under nuclear reactor environments is of both fundamental and technological importance. In the past, Brink et al. [12] have reported reactor neutron flux irradiation on $\mathrm{SiC}$ polytypes in the fluence range of $10^{15}-10^{16} \mathrm{ncm}^{-2}$. The results have shown noticeable modification in the IR transmission and Raman spectral features due to the formation of point defects (acting as traps for free carriers). Wendler et al. [13] have 
reported Urbach type of absorption in the range $3.2-3.3 \mathrm{eV}$ and decrease of the Raman intensity in the fluence range of $10^{17}-10^{19} \mathrm{ncm}^{-2}$. No linear dependence of LO and TO modes were found with respect to neutron fluence or defect concentration. Several new PL bands related to extended defects were detected in 3C-SiC polytype [14]. Few deep level transient spectroscopy (DLTS) reports are also available on neutron-induced defects in $4 \mathrm{H}-\mathrm{SiC}[9,15]$. Most of the studies are limited to either to the structural properties or electrical properties independently. The present article is intended to report on the thermal neutron irradiation (NI) effects on n-type $4 \mathrm{H}-\mathrm{SiC}$ by studying both structural and electrical properties. The structural modifications were accounted by using X-Ray diffraction (XRD), UV-Vis absorption, photoluminescence (PL) and Raman spectroscopy techniques. The practical consequences of NI-induced modifications were realized by studying the current-voltage $(I-V)$ characteristics of the $\mathrm{Al} / \mathrm{n}-4 \mathrm{H}-\mathrm{SiC}$ Schottky contacts. The combined structural and electrical studies were correlated with bulk information of the material under study.

\section{Experimental}

The commercially available standard two inch n-type $4 \mathrm{H}-\mathrm{SiC}$ $\langle 0001\rangle$ wafers were procured from Semiconductor Wafer Inc, Taiwan. The resistivity of the wafer was $0.012-0.03 \Omega \mathrm{cm}$. The density and thickness of the wafer was $3.21 \mathrm{~g} \mathrm{~cm}^{-3}$ and $330 \pm 25 \mu \mathrm{m}$, respectively. The wafer was diced into approximately $0.5 \times 0.5$ and $1 \times 1 \mathrm{~cm}$ squares using a diamond tip scriber. The diced samples are then cleaned according to the standard procedures as described in our previous studies $[16,17]$. The Al Schottky contacts on the cleaned $1 \times 1 \mathrm{~cm}$ samples were formed by thermal evaporation technique. A prepared shadow mask of circular diameters $0.2 \mathrm{~cm}$ were employed to obtain Schottky contacts. The Al deposition was carried out at the deposition rate of $3 \AA / \mathrm{s}$ under the vacuum pressure of $8 \times 10^{-6} \mathrm{mbar}$. The thickness of $\mathrm{Al}$ was kept at $\sim 50 \mathrm{~nm}$ by monitoring through digital thickness monitor (DTM).

The neutron irradiation (NI) on $\mathrm{n}-4 \mathrm{H}-\mathrm{SiC}$ and $\mathrm{Al} / \mathrm{n}$ 4H-SiC Schottky contacts were carried out at Dhruva research nuclear reactor, Bhabha Atomic Research Centre (BARC) Trombay India. The samples were packed in the $\mathrm{Al}$ foil and kept for irradiation in the reactor environment. The thermal neutron flux at the sample position was $\sim 1.5 \times 10^{13} \mathrm{ncm}^{-2} \mathrm{~s}^{-1}$. All the samples were irradiated up to a fluence of $\sim 7.5 \times 10^{16} \mathrm{ncm}^{-2}$. After NI, the samples were kept under a cooling period of $\sim 24 \mathrm{~h}$.

The XRD pattern of the samples were collected in $2 \theta$ range of $20^{\circ}-80^{\circ}$ using bench top Rigaku MiniFlex 600 powder diffractometer $(\lambda=1.5402 \AA, 40 \mathrm{kV}, 15 \mathrm{~mA})$ under $\theta-2 \theta$ geometry condition. The Raman spectra of the samples were recorded in the back scattering symmetry using Horiba LABRAM-HR Evolution Raman visible spectrometer. The spectra was measured by exciting sample with $633 \mathrm{~nm}$ laser which was focused to a spot size of diameter $2 \mu \mathrm{m}$. The spectrometer was calibrated by using silicon which has a Raman mode at $520.6 \mathrm{~cm}^{-1}$. The absorption spectra of the samples were collected by using Shimadzu UV-1800 spectrophotometer. The optical absorption coefficient $(\alpha)$ after irradiation was calculated by assuming uniformity in the damage over the whole thickness, which allows a direct calculation based on Beer-Lambert's law and in all cases the refractive index was assumed to be unchanged [13]. The Photoluminescence (PL) spectra were measured using Horiba Jobin Yvon $450 \mathrm{~W}$ Illuminator. The spectra was measured at an excitation wavelength of $325 \mathrm{~nm}$ at room temperature and in the wavelength range of $350-620 \mathrm{~nm}$. The current-voltage $(I-V)$ characteristics of $\mathrm{Al} / \mathrm{n}-4 \mathrm{H}-\mathrm{SiC}$ Schottky contacts were carried out using Keithley 2450 source meter. The spring loaded Al pressure contacts were used as back ohmic contacts during $I-V$ characterization [17].

\section{Results and discussion}

\subsection{XRD analysis of $n-4 H-S i C$}

Figure 1 shows (0008) reflection of $\mathrm{n}-4 \mathrm{H}-\mathrm{SiC}$ before and after NI at the irradiation fluence of $\sim 7.5 \times 10^{16} \mathrm{n} \mathrm{cm}^{-2}$. As noticed, irradiated sample have shown peak shift towards the higher side. This suggesting a decrease in the $c$-axis lattice constant of the material, where $c$ can be evaluated by using the relation [18]:

$c=\frac{\lambda \times l}{2 \sin \theta_{00 l}}$,

where $\lambda=1.5402 \AA$. The change in the lattice constant $(\Delta c / c)$ was found to be $1.36 \times 10^{-3}$. Such a decrease is mainly attributed to neutron-induced isotopic modifications and formation of defects in the material. A similar decrease in the lattice parameter has been noticed in diamond with the increase of ${ }_{6}^{13} \mathrm{C}$ isotope $[11,19]$.

\subsection{UV-Vis absorption spectra analysis of $n-4 H-S i C$}

Figure 2 shows the optical absorption spectra of $\mathrm{n}-4 \mathrm{H}-\mathrm{SiC}$ before and after NI at the irradiation fluence of $\sim 7.5 \times 10^{16} \mathrm{ncm}^{-2}$. The four characteristic features as marked are the representative of band to band (a), band to donor level and extended states (Urbach tail) (b), free electron absorption into higher conduction bands (c) and bands from defect states (d). The doping type, n-type (or 


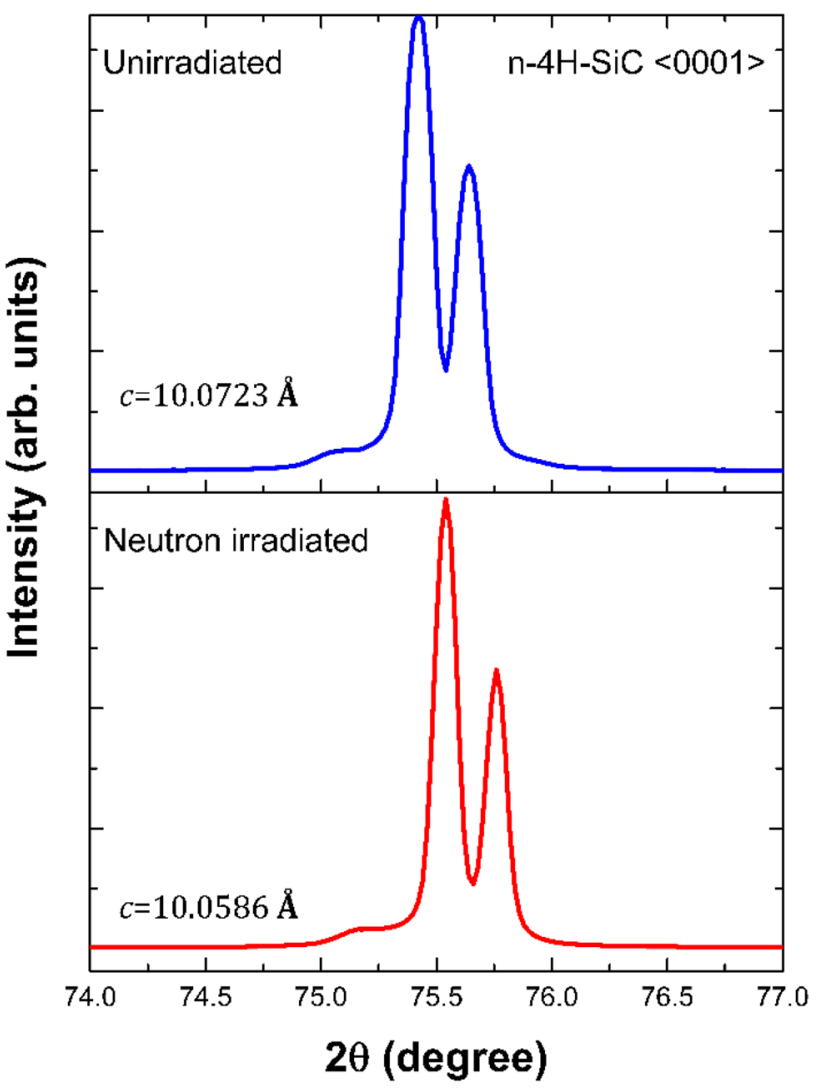

Fig. 1 XRD depicting (0008) XRD reflection of $n-4 H-S i C$ before and after neutron irradiation

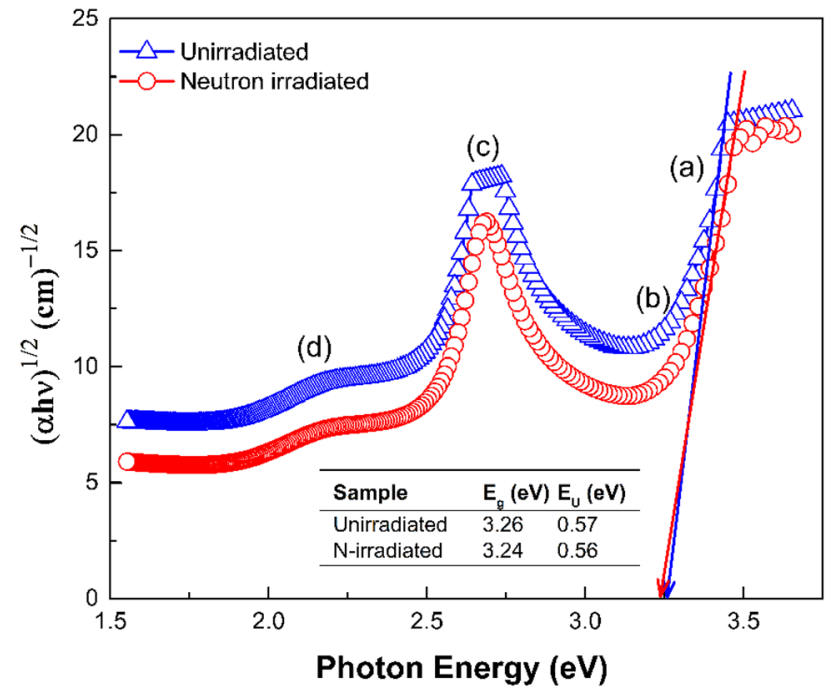

Fig. 2 Absorption spectra of $\mathrm{n}-4 \mathrm{H}-\mathrm{SiC}$ before and after neutron irradiation [inset table shows the variation in optical energy bandgap $\left(E_{g}\right)$ and Urbach energy $\left.\left(E_{U}\right)\right]$ p-type) can be seen from the presence (or absence) of the free electron absorption band or Biedermann absorption bands (c). These bands are known to be responsible for the green-brownish colour of polytypes [18, 20, 21]. After NI, marginal variations in the absorption spectra were observed such as shift in the absorption band edge (a), increased tailing (or widening) of the absorption edge (b) and the narrowing of absorption bands (c) and (d). By fitting Tauc's equation [22] for an indirect allowed transitions in the region (a), the band gap $E_{\mathrm{g}}$ of the sample was estimated. A decrease in $E_{\mathrm{g}}$ of $\sim 0.2 \mathrm{eV}$ has been noticed in the irradiated sample. While well below $E_{\mathrm{g}}$, the estimation of Urbach energy $E_{\mathrm{U}}$ has resulted in the decrease of $\sim 0.01 \mathrm{eV}$. Thus as seen from Fig. 2 the overall decrease in absorption coefficient $\alpha, E_{\mathrm{g}}$ and $E_{\mathrm{U}}$ of the irradiated sample are attributed to structural modifications induced by thermal neutrons in the material.

\subsection{Raman spectra analysis of $n-4 H-S i C$}

Figure 3 shows the first order Raman spectra (FORS) of $\mathrm{n}-4 \mathrm{H}-\mathrm{SiC}$ before and after NI. The different phonon modes are as labelled in the spectra [23]. In the irradiated sample, no new bands were observed in the phonon energy range of $100-1800 \mathrm{~cm}^{-1}$. Also no homo nuclear $\mathrm{Si}-\mathrm{Si}$ and $\mathrm{C}-\mathrm{C}$ bonds were detected in the irradiated sample, indicating no irradiation-induced amorphization effects in the material [22, 24]. However, marginal decrease in the intensity and increase in width of the $E_{2}(\mathrm{FTO})$ mode has been noticed. This could be due to neutron-induced isotopic effects in the material. In addition to that the LOPC (longitudinal

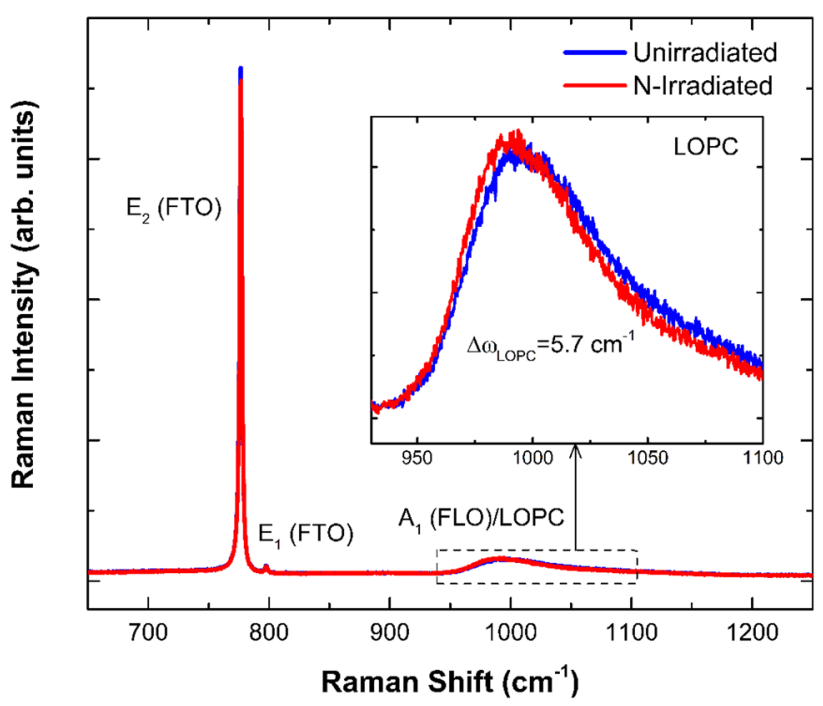

Fig. 3 First order Raman spectra of $n-4 H-S i C$ before and after neutron irradiation. The inset plot shows the modification in the LOPC mode 
optical phonon-plasmon coupling) mode have shown noticeable shift of $5.7 \mathrm{~cm}^{-1}$ towards the lower phonon energies (inset, Fig. 3). A similar shift up to $3 \mathrm{~cm}^{-1}$ have been reported previously by Brink et al. [12]. Such a shift towards lower phonon energies suggests decrease in the free carrier concentration $\left(n_{\mathrm{e}}\right)$. By considering empirical relation $n_{\mathrm{e}}=\Delta \omega^{1.0} \times 1.23 \times 10^{17} \mathrm{~cm}^{-3}$ deduced by Nakashima et al. [25], it is estimated that $n_{e}$ of the unirradiated and neutron irradiated samples were about $4.2 \times 10^{18}$ and $3.5 \times 10^{18} \mathrm{~cm}^{-3}$ respectively. Such a decrease in $n_{\mathrm{e}}$ of the neutron-irradiated sample indicates the capture of free charge carriers by native defects or irradiation-induced defects in the material (compensation effects).

\subsection{PL spectra analysis of $n-4 H-S i C$}

Figure 4 shows the PL spectra of $\mathrm{n}-4 \mathrm{H}-\mathrm{SiC}$ before and after $\mathrm{NI}$ measured at $\sim 300 \mathrm{~K}$ and $325 \mathrm{~nm}$ excitation. As noticed the distribution of PL intensity is remarkably varied after NI. A broad defect related PL band (DPL) around $\sim 2.35 \mathrm{eV}$ is observed in both the samples. The main radiative recombination path of DPL occurs via donor-acceptor pairs (DAP) of the $N$-impurities and $N$-impurities associated with the intrinsic defects such as $V_{\mathrm{C}}$ and $C_{\mathrm{i}}$ (carbon interstitials) $[18,26]$. On the other hand a broad but less intense PL band observed near the band edge is attributed to recombination of nitrogen bound excitons (NBE) [10, 27]. But, NBE PL signal was not detectable in the neutron irradiated sample. The similar quenching effects have been reported earlier in the high energy neutron irradiated $4 \mathrm{H}-\mathrm{SiC}$, where the authors attribute such effects for lattice damage due to induced defects in the material [10]. But in the present study no significant

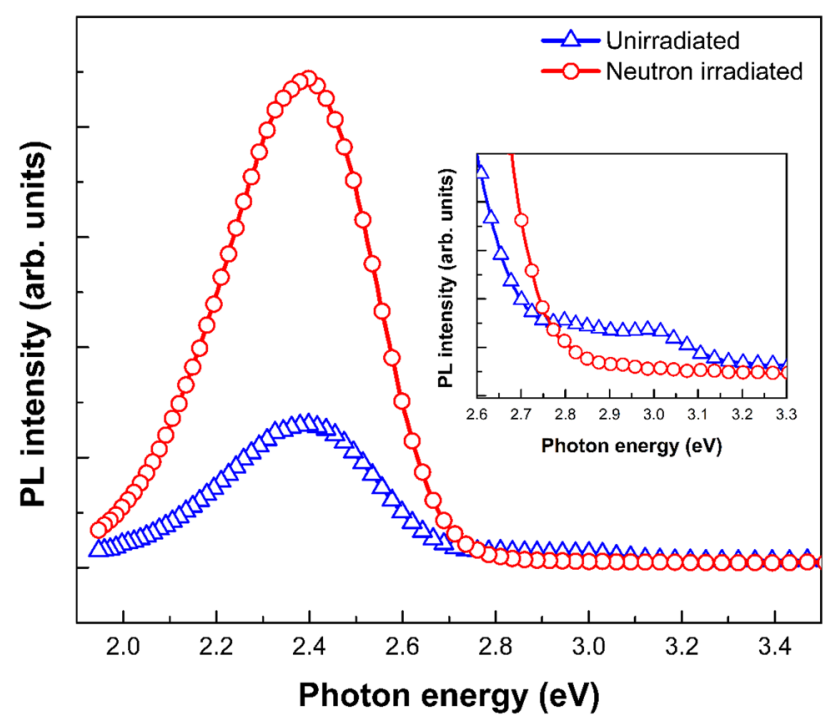

Fig. 4 Room temperature photoluminescence (RTPL) spectra of $\mathrm{n}-4 \mathrm{H}-\mathrm{SiC}$ before and after neutron irradiation lattice damage was noticed. But apparently, PL quenching could be caused due to the passivation of dopants ( $\mathrm{N}$ - or NIinduced $P$-dopants) by grown-in defects, which may in turn leading to charge carrier compensation effects or decrease in $n_{\mathrm{e}}$. This resulting in the increase of DPL intensity as opposed to that of the NBE band. The $Z_{1 / 2}$ defects are usually much anticipated in the compensation effects [28], due to which $n_{\mathrm{e}}$ was found to decrease in the irradiated sample (Sect. 3.3).

\subsection{I-V characteristics of Al/n-4H-SiC Schottky contacts}

Figure 5 shows the current-voltage $(I-V)$ characteristics of $\mathrm{Al} / \mathrm{n}-4 \mathrm{H}-\mathrm{SiC}$ Schottky contacts before and after NI at the fluence of $\sim 7.5 \times 10^{16} \mathrm{ncm}^{-2}$. As expected the decrease in the forward and reverse currents are caused due to decrease in $n_{e}$ due to compensation effects in $\mathrm{n}-4 \mathrm{H}-\mathrm{SiC}$ (Figs. 3, inset and 4). In addition to that, an important characteristic feature observed in the irradiated Schottky contacts is the zero-bias offset and the resemblance of double switch-on feature. This type of behaviour was also previously observed in the electron and gamma irradiated $\mathrm{Al} / \mathrm{n}-4 \mathrm{H}-\mathrm{SiC}$ Schottky contacts [17]. Such a behaviour is mainly attributed to the influence of irradiation-induced defects in the $\mathrm{n}-4 \mathrm{H}-\mathrm{SiC}$ bulk and their role in the tunnelling mechanism than modification in the interface chemistry of the junction [17].

The Schottky contact parameters ideality factor $(\eta)$ and Schottky barrier height $\left(\Phi_{\mathrm{B}}\right)$ were evaluated with and without considering the effects of series resistance $\left(R_{\mathrm{S}}\right)$ of the junction in the similar to our previous studies on $\mathrm{Al} / \mathrm{n}-4 \mathrm{H}-\mathrm{SiC}$ Schottky contacts [17]. The semi log and Cheung plots are shown Fig. $6 a$ and $b$, respectively, and the obtained values from these plots are reported in Table 1. The discrepancy observed in $\eta$

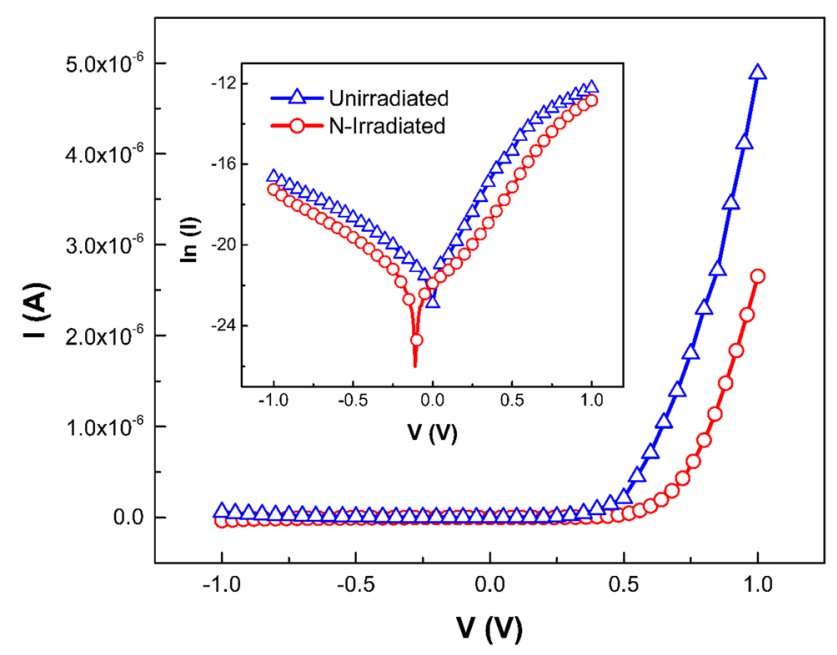

Fig. $5 I-V$ characteristics of $\mathrm{Al} / \mathrm{n}-4 \mathrm{H}-\mathrm{SiC}$ Schottky contacts before and after neutron irradiation. Inset shows the semi-log plot of the $I-V$ characteristics 
Fig. 6 a Semi log plot, b Cheung plots of unirradiated and neutron irradiated $\mathrm{Al} / \mathrm{n}-4 \mathrm{H}-$ SiC Schottky contacts
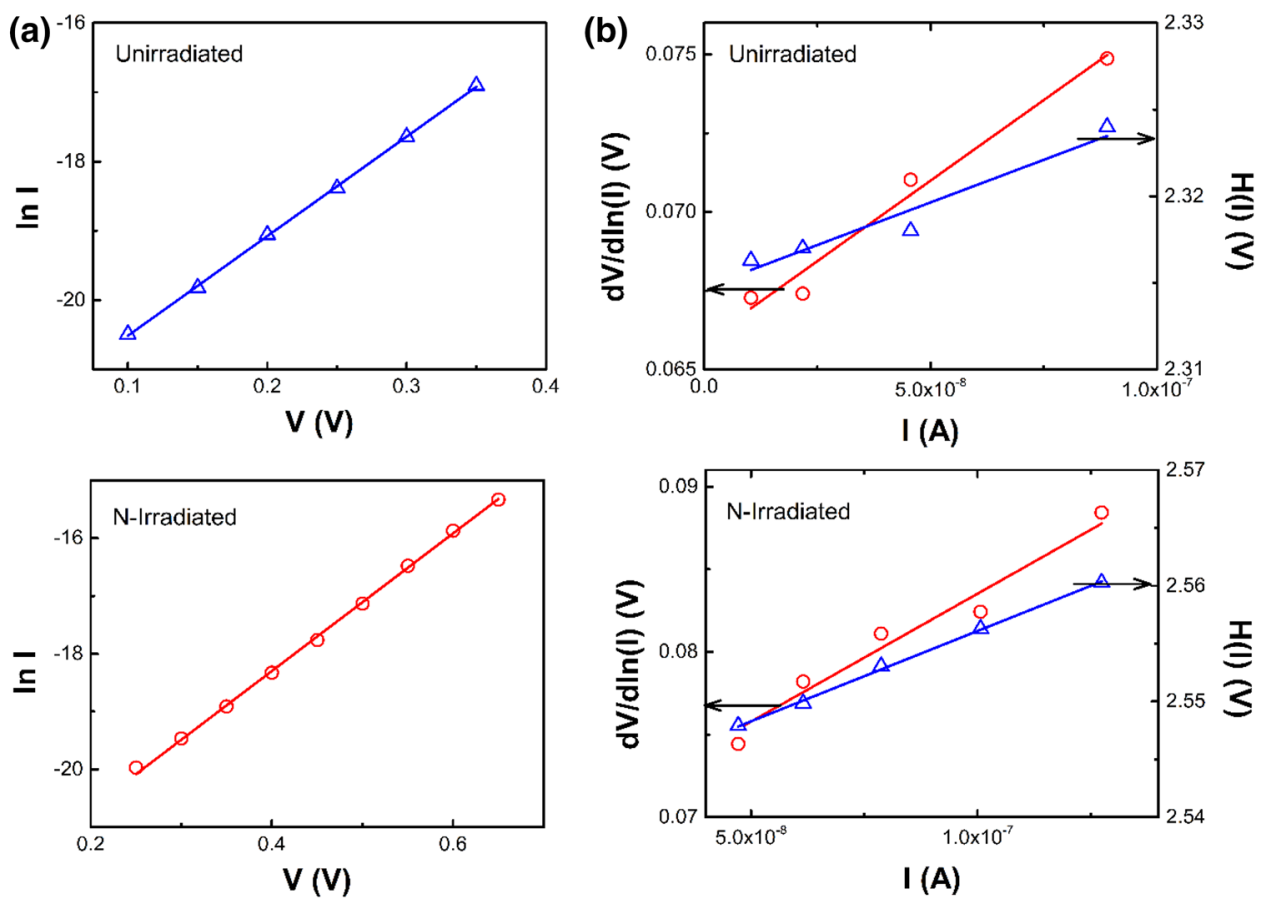

Table $1 \mathrm{Al} / \mathrm{n}-4 \mathrm{H}-\mathrm{SiC}$ Schottky contact parameters before and after neutron irradiation

\begin{tabular}{lllllll}
\hline & \multicolumn{2}{l}{ TE model } & & \multicolumn{3}{l}{ Cheung model } \\
\cline { 2 - 3 } Sample & $\eta$ & $\Phi_{\mathrm{B}}(\mathrm{eV})$ & & $\eta$ & $\Phi_{\mathrm{B}}(\mathrm{eV})$ & $\mathrm{R}_{\mathrm{s}}(\mathrm{k} \Omega)$ \\
\hline Unirradiated & 2.69 & 0.90 & & 2.55 & 0.91 & 102.3 \\
$n$-Irradiated & 3.25 & 0.93 & & 2.63 & 0.97 & 151.7 \\
\hline
\end{tabular}

and $\Phi_{\mathrm{B}}$ values evaluated from the semi log and Cheung plots are attributed to $R_{\mathrm{S}}$ of the junction. Both Schottky contacts have shown $\eta>1$. This suggests inhomogeneous or non-ideal nature of the Schottky junction [29, 30]. In the present case such a deviation is attributed to the lattice mismatch between $\mathrm{n}-4 \mathrm{H}-\mathrm{SiC}$ and $\mathrm{Al}$, presence of impurities states (processed and irradiation-induced) in the interface as well as bulk of the crystal. In fact, the obtained $\Phi_{\mathrm{B}}$ value of $0.91 \mathrm{eV}$ indicates the pinning of Fermi level $\left(E_{F}\right)$ due to the presence of defect level at $E_{\mathrm{c}}-2.35 \mathrm{eV}$ (Fig. 4) [17]. On the other hand the increase in $\eta, \Phi_{B}$ and $R_{S}$ of neutron irradiated Schottky contacts are attributed to neutron-induced modifications in $\mathrm{n}-4 \mathrm{H}-\mathrm{SiC}$ i.e. decrease in lattice parameter due to isotopic effects (Fig. 1) and decrease in $n_{\mathrm{e}}$ (inset, Fig. 3) due to formation of defects (Fig. 4). Thus noticeable modifications were observed in the neutron irradiated Schottky contacts.

\section{Conclusion}

The thermal neutron irradiation effects on the structural and electrical properties of $n-4 \mathrm{H}-\mathrm{SiC}$ and $n-\mathrm{Al} / \mathrm{n}-4 \mathrm{H}-\mathrm{SiC}$ Schottky contacts were studied. XRD studies revealed a decrease in the lattice parameter of the irradiated samples due to isotopic modifications and irradiation-induced defects in the material. The $E_{\mathrm{g}}, E_{\mathrm{U}}, n_{\mathrm{e}}$ and PL bands of $\mathrm{n}-4 \mathrm{H}-\mathrm{SiC}$ were noticeably affected due to isotopic modification and accumulation of defects in the material. Due to which the $I-V$ characteristics of $\mathrm{Al} / \mathrm{n}-4 \mathrm{H}-\mathrm{SiC}$ Schottky contacts were substantially affected in terms of irradiationinduced zero-bias offset as well as increase in the contact parameters such as $\Phi_{\mathrm{B}}, \eta$ and $R_{\mathrm{S}}$ of the junction.

Acknowledgements Open access funding provided by Manipal Academy of Higher Education, Manipal. This work has been carried out under UGC DAE CSR Mumbai, India collaborative research scheme (UDCSR/MUM/AO/CRS-M-278/2017/575). The authors would like to acknowledge Dr. P.D. Babu, UGC DAE CSR, Mumbai and Dr. Rekha Rao, SSPD BARC, India for extending their support. The authors also acknowledge Sahana Nagappa Moger, MIT, Manipal for assisting in the thermal deposition of Al.

Open Access This article is licensed under a Creative Commons Attribution 4.0 International License, which permits use, sharing, adaptation, distribution and reproduction in any medium or format, as long as you give appropriate credit to the original author(s) and the source, provide a link to the Creative Commons licence, and indicate if changes were made. The images or other third party material in this article are included in the article's Creative Commons licence, unless indicated otherwise in a credit line to the material. If material is not included in the article's Creative Commons licence and your intended use is not 
permitted by statutory regulation or exceeds the permitted use, you will need to obtain permission directly from the copyright holder. To view a copy of this licence, visit http://creativecommons.org/licenses/by/4.0/.

\section{References}

1. T. Kimoto, J.A. Cooper, Fundamentals of Silicon Carbide Technology: Growth, Characterization, Devices and Applications (Wiley, Hoboken, 2014)

2. F. Nava, G. Bertuccio, A. Cavallini, E. Vittone, Silicon carbide and its use as a radiation detector material. Meas. Sci. Technol. 19, 102001 (2008)

3. F. Nava, A. Castaldini, A. Cavallini, P. Errani, V. Cindro, Radiation detection properties of $4 \mathrm{H}-\mathrm{SiC}$ schottky diodes irradiated up to $1016 \mathrm{n} / \mathrm{cm} 2$ by $1 \mathrm{MeV}$ neutrons. IEEE Trans. Nucl. Sci. 53, 2977-2982 (2006)

4. F. Moscatelli, A. Scorzoni, A. Poggi, M. Bruzzi, S. Sciortino, S. Lagomarsino, G. Wagner, I. Mandic, R. Nipoti, Radiation hardness after very high neutron irradiation of minimum ionizing particle detectors based on $4 \mathrm{H}-\mathrm{SiC} \mathrm{p}+\mathrm{n}$ junctions. IEEE Trans. Nucl. Sci. 53, 1557-1563 (2006)

5. F. Moscatelli, A. Scorzoni, A. Poggi, R. Nipoti, Annealing effects on leakage current and epilayer doping concentration of $\mathrm{p}+\mathrm{n}$ junction $4 \mathrm{H}-\mathrm{SiC}$ diodes after high energy neutron irradiation. NIMA 583, 173-176 (2007)

6. J.A. Kulisek, T.E. Blue, Neutron and proton radiation damage and isothermal annealing of irradiated SiC Schottky power diodes. AIP Conf. Proc. 1103, 478 (2009)

7. Z. Lin, Z. Yimen, Z. Yuming, H. Chao, Neutron radiation effect on 4H-SiC MESFETs and SBDs. J. Semicond. 31, 114006-1114006-6 (2010)

8. J. Wu, Y. Jiang, J. Lei, X. Fan, Y. Chen, M. Li, D. Zou, B. Liu, Effect of neutron irradiation on charge collection efficiency in 4H-SiC Schottky diode. Nucl. Instrum. Methods Phys. Res. A 735, 218-222 (2014)

9. P. Hazdra, V. Záhlava, J. Vobecky, Point defects in 4H-SiC epilayers introduced by neutron irradiation. Nucl. Instrum. Methods Phys. Res. B 327, 124-127 (2014)

10. L. Liu, A. Liu, S. Bai, L. Lv, P. Jin, X. Ouyang, Radiation resistance of silicon carbide Schottky diode detectors in D-T fusion neutron detection. Sci. Rep. 7, 13376 (2017)

11. E.E. Haller, Isotopically engineered semiconductors. J. Appl. Phys. 77, 2857 (1995)

12. D.J. Brink, J.B. Malherbe, J. Camassel, Neutron irradiation effects in SiC. Nucl. Instrum. Methods Phys. Res. B 267, 2716-2718 (2009)

13. E. Wendler, Th Biershenk, F. Felgentrager, J. Sommerfeld, W. Wesch, D. Alber, G. Bukalis, L.C. Prinsloo, N. van der Berg, E. Friedland, J.B. Malherbe, Damage formation and optical absorption in neutron irradiated SiC. Nucl. Instrum. Meth. Phys. Res. B 286, 97-101 (2012)

14. V. Bratus, R. Melnyk, O. Kolomys, B. Shanina, V. Strelchuk, Photoluminescence spectroscopy of neutron-irradiated cubic SiC crystals. Mater. Sci. Forum 740-742, 417-420 (2013)

15. T. Brodara, I. Capana, V. Radulović, L. Snojb, Ž. Pastuović, J. Coutinhod, T. Ohshima, Laplace DLTS study of deep defects created in neutron-irradiated n-type $4 \mathrm{H}-\mathrm{SiC}$. Nucl. Instrum. Methods Phys. Res. B 437, 27-31 (2018)

16. I.P. Vali, P.K. Shetty, M.G. Mahesha, R. Keshav, V.G. Sathe, D.M. Phase, R.J. Choudhary, Gamma irradiation effects on Al/n-Si Schottky junction properties. Nucl. Instrum. Methods Phys. Res. B 436, 191-197 (2018)

17. I.P. Vali, P.K. Shetty, M.G. Mahesha, V.C. Petwal, J. Dwivedi, D.M. Phase, R.J. Choudhary, Electron and gamma irradiation effects on Al/n-4H-SiC Schottky contacts. Vacuum 172, 109068 (2020)

18. I.P. Vali, P.K. Shetty, M.G. Mahesha, V.G. Sathe, D.M. Phase, R.J. Choudhary, Structural and optical studies of gamma irradiated N-doped 4H-SiC. Nucl. Instrum. Methods Phys. Res. B 440, 101-106 (2019)

19. H. Holloway, K.C. Hass, M.A. Tamor, T.R. Anthony, W.F. Banholzer, Isotopic dependence of the lattice constant of diamond. Phys. Rev. B. 13, 7123-7126 (1991)

20. E. Biedermann, The optical absorption bands and their anisotropy in the various modifications of SiC. Solid State Commun. 3, 343-346 (1965)

21. P.J. Wellmann, S. Bushevoy, R. Weingärtner, Evaluation of n-type doping of $4 \mathrm{H}-\mathrm{SiC}$ and $\mathrm{n}$-/p-type doping of $6 \mathrm{H}-\mathrm{SiC}$ using absorption measurements. Mater. Sci. Eng. B. 80, 352-356 (2001)

22. S. Sorieul, X. Kerbiriou, J.-M. Costantini, L. Gosmain, G. Calas, C. Trautmann, Optical spectroscopy study of damage induced in $4 \mathrm{H}-\mathrm{SiC}$ by swift heavy ion irradiation. J. Phys. Condens. Matter 24, 125801 (2012)

23. S. Nakashima, H. Harima, Raman investigation of $\mathrm{SiC}$ polytypes. Phys. Status Solidi Appl. Res. 162, 39-64 (1997)

24. P.F. Wang, L. Huang, W. Zhu, Y.F. Ruan, Raman scattering of neutron irradiated $6 \mathrm{H}-\mathrm{SiC}$. Solid State Commun. 152, 887-890 (2012)

25. S. Nakashima, T. Kitamura, T. Kato, K. Kojima, R. Kosugi, H. Okumura, H. Tsuchida, M. Ito, Determination of free carrier density in the low doping regime of $4 \mathrm{H}-\mathrm{SiC}$ by Raman scattering. Appl. Phys. Lett. 93, 121913 (2008)

26. A.A. Lebedev, B.Y. Ber, N.V. Seredova, D.Y. Kazantsev, V.V. Kozlovski, Radiation-stimulated photoluminescence in electron irradiated 4H-SiC. J. Phys. D. 48, 485106 (2015)

27. E.V. Kalinina, N.A. Chuchvaga, E.V. Bogdanova, A.M. Strel'chuk, D.B. Shustov, M.V. Zamoryanskaya, V.A. Skuratov, Optical and electrical properties of $4 \mathrm{H}-\mathrm{SiC}$ irradiated with $\mathrm{Xe}$ ions. Semiconductors 48, 156-162 (2014)

28. K. Kawahara, X.T. Trinh, N.T. Son, E. Janzén, J. Suda, T. Kimoto, Investigation on origin of $\mathrm{Z} 1 / 2$ centre in $\mathrm{SiC}$ by deep level transient spectroscopy and electron paramagnetic resonance. Appl. Phys. Lett. 102, 112106 (2013)

29. S.M. Sze, Physics of Semiconductor Devices, 2nd edn. (Wiley, Hoboken, 1981)

30. E.H. Rhoderick, R.H. Williams, Metal-Semiconductor Contacts, 2nd edn. (Oxford Science Publication, Oxford, 1988)

Publisher's Note Springer Nature remains neutral with regard to jurisdictional claims in published maps and institutional affiliations. 